\title{
REFLEXIONES SOBRE LA CRÍTICA DE BERGBOHM A LA DOCTRINA DEL DERECHO NATURAL*
}

\section{El derecho natural y el concepto del derecho}

El derecho natural se presenta como teniendo ciertas propiedades y fuentes que lo hacen superior al derecho positivo. B. intentará demostrar que tales propiedades no son posibles y que sus pretendidas fuentes son incapaces para formar el derecho. Así se habrá refutado el derecho natural de modo puramente filosófico, sin considerar las consecuencias que tiene para el orden jurídico (lo cual constituyó el tema de la primera parte).

Podemos aquí ser más breves, pues más de una vez bastará con recordar nuestras consideraciones anteriores, ya que nuestro autor procede, a veces, tam. bién así.

B. Examina separadamente las propiedades y las fuentes del derecho natural.

A) El derecho natural pretende ser eterno, universal, absoluto. Pero estas propiedades, objeta $B$., contradicen a la relatividad del derecho, pues ninguna materia que no esté condicionada por el espacio, el tiempo, las circunstancias, etc., puede ser regulada por él. El derecho tiene que obrar sobre acciones, relaciones, estados. Vive de las cosas que le están sometidas, de lo contrario no puede existir: si p. ej. no hay representación popular, no puede haber ley de elecciones; donde no hay diarios no puede haber ley de prensa, etc. Por lo tanto, no puede haber preceptos eternos.

Si se objeta que no se trata de preceptos sino de conceptos y de principios supremos, $B$. replica que esto es insostenible en virtud del carácter cerrado de todo derecho, según intentó demostrarlo en la primera parte.

Si se sostiene que sólo hay principios eternos para modos de obrar eternos (homicidio, contratos, etc.) B. objeta que no hay hechos iguales -ni en las relaciones naturales ni en los estados culturales. No pueden reducirse a igualdad las necesidades y fuerzas que dan impulso a las acciones o determinan las orientaciones del obrar. Nada más diverso que los fines que se proponen los hombres y los medios que utilizan. La Historia y la Etnografía ponen de manifiesto las más grandes diferencias. $B$. admite la constancia en sentimientos e instintos, pero

* Continuación. Véase Diánoia, Año XI, núm. 11, 1965. 
como el derecho no aprehende a éstos sino a las acciones que las exteriorizan y que son cambiantes, no puede haber un derecho eterno, absoluto, universal. No se puede formular un solo precepto jurídico con carácter eterno, ni siquiera el de "no debes matar" (pp. 410-420). Y aquí $B$. exhibe en una larga nota todas las excepciones a este precepto (pp. 420-23).

En estas críticas $B$. päte de hechos exactos, pero los generaliza en tal medida que sus conclusiones son falsas. Su error consiste principalmente en tomar la parte por el todo. Dejo de lado el primer ejemplo citado, que está mal elegido, pues la representación popular que ha de dar lugar a la ley de elecciones no es un hecho sino también el resultado de otra ley. Aquí no hay condicionamiento del derecho por un hecho, sino de una ley por otra ley. Pero el ejemplo de los diarios y de la ley de imprenta es aleccionador para mostrar que los hechos nuevos, el cambio de las circunstancias, etc., no hacen imposible el derecho natural. Supongamos, como es lo corriente, que una ley de prensa, entre otras cosas, garantiza la libertad de la prensa, configura el delito de imprenta y establece el derecho de respuesta. Es claro que el derecho natural nada dispone sobre prensa. Pero es un derecho natural la libre expresión del propio pensamiento y la facultad de defenderse de un ataque injusto. La injuria, la calumnia, la falsedad, son acciones injustas porque lesionan el honor y el buen nombre de la persona, que son derechos naturales de ésta, así como el derecho al conocimiento de la verdad. La ley de prensa es la determinación y especificación, protegiéndolas o sancionándolas, de las acciones lícitas e ilícitas que derivan de aquellos derechos en el supuesto de que se ejercen por medio de los diarios y periódicos. Lo mismo se ha hecho después con el telégrafo y la radio. Pero diario, telégrafo, radio, así como teléfono, altoparlante, teletipo, etc., no son sino medios técnicos diferentes al servicio de un mismo fin: la comunicación de pensamientos, de verdades y falsedades, de injurias y de elogios... Todos han sido o pueden ser objeto de regulación por el derecho positivo. $\mathrm{Y}$ éste puede adaptar y especificar los principios de derecho natural a cada uno de esos medios.

Aquí encontramos una relacionalidad de los hechos con el derecho positivo. $\mathrm{Si}$ no surgen esos hechos, no puede haber tampoco el derecho que los regula. Si no existen diarios impresos no puede haber ley de imprenta. Pero esa condicionalidad de la ley por los hechos sólo determina la existencia de la ley, de ninguna manera su contenido, el modo propio de su regulación. Esta puede variar, determinando de varios modos los principios del derecho natural, por ejemplo, estableciendo quiénes son los responsables según que los artículos estén firmados o no, obligando a la firma o estableciendo la publicidad del nombre del director del diario, etc. Es claro que la ley puede también hacer caso omiso de los principios del derecho natural, por ejemplo estableciendo la censura previa o dejando sin sanción las calumnias e injurias. Entonces el derecho natural es violado o queda sin protección. Pero esto no significa que éste no exista. Siempre habrá un grupo de hombres que tenga clara conciencia de él y clame por su reconoci- 
miento. La ley de imprenta o la ley de radiocomunicaciones son contingentes porque los hechos técnicos que regulan son contingentes también. Y así como esas leyes surgieron porque aparecieron esos hechos, si mañana los hombres no fabricaran más imprentas o aparatos de radio, las leyes respectivas no tendrían ya razón de ser. En cambio, la comunicación de los pensamientos más acá de todos los medios técnicos para difundirlos, es un hecho universal humano y es a él al que se refieren los principios del derecho natural.

Que el derecho natural no es un sistema cerrado y que aunque lo fuera no impediría su especificación por un sistema más concreto de disposiciones, ya lo hemos demostrado en la primera parte. $\mathrm{Y}$ las explicaciones que hemos dado sobre la ley de imprenta evidencian en un caso particular cómo ello es posible.

No discutiremos aquí el problema metafísico de si el derecho natural es eterno y si existiría aun cuando no existieran los entes a quienes va dirigido. Pero el derecho natural es invariable en el espacio y en el tiempo en la misma medida en que es invariable la naturaleza humana y en que realiza constantemente ciertas acciones. $B$. lo niega en forma tan absoluta que no es difícil mostrar su error. Admite la constancia de los sentimientos e instintos en todos los hombres, pero sostiene que los hechos y acciones no son iguales. Pero su argumento prueba demasiado, pues, de ser exacto, no sólo no existiría derecho natural sino que el mismo derecho positivo sería imposible en cuanto formula reglas generales. Es claro que las acciones consideradas en todos sus elementos son individuales e irrepetibles. Pero contienen elementos comunes que pueden abstraerse en diverso grado de generalidad y que son los que el derecho positivo tipifica y regula. Así ocurre con los diversos tipos de contratos y de delitos. Éstos pueden variar dentro de ciertos límites. Por ejemplo la existencia o inexistencia de la moneda determina que se tipifique o no la compraventa, el préstamo, la falsificación de moneda, etcétera. Pero hay ciertas acciones que el hombre puede ejecutar siempre, cualesquiera sean los medios que emplee: poseer, unirse a una persona del otro sexo, trabajar, amenazar o lesionar la vida o los bienes ajenos, etc. Lo que importa señalar ante todo es que tales acciones existen - aparte de cómo se especifiquen e individualicen-- y que no es exacto reducir la constancia sólo a los sentimientos y a los instintos, como pretendía $B$. Éstas son las acciones que el derecho natural regula por medio de principios, que son muy generales porque sólo en esa medida de generalidad son constantes e invariables las acciones que el hombre realiza. En materia contractual, por ejemplo, rige el principio de derecho natural de que los contratos deben cumplirse, y cumplirse de buena fe. El derecho lo especifica aplicándolo a los diferentes tipos de contrato y supliendo la voluntad presunta de las partes. Puede limitarlo por determinadas razones, pero no puede ignorarlo ni eliminarlo.

Además de la condicionalidad del derecho por su materia diversa, arguye $B$. la variabilidad del derecho respecto a una misma materia. 
El ejemplo a que acude es el precepto de no matar, destacado ya anteriormente por Wundt, porque aparentemente es el más universal. $B$. se complace en mostrar todas las excepciones que el mencionado precepto ha tenido en la historia y en los diversos pueblos. La cuestión ya ha sido discutida muchas veces. Pero no puede ser resuelta satisfactoriamente si no se hacen ciertas distinciones. En primer lugar, hay que decir que aunque se suponga que el derecho natural prohibe matar en forma absoluta, esto es, sin ninguna excepción, las excepciones históricas no demostrarian que el principio carece de validez, sino solamente que los hombres no han tenido siempre y en todas partes el conocimiento adecuado de toda su amplitud. Es un prejuicio bastante corriente el creer que si se admite el derecho natural, hay que admitir también que el conocimiento de sus principios es de por sí evidente para todos los hombres. Pero como no hay ideas innatas, los principios éticos, sean valores o normas, requieren también ser descubiertos, como cualquier otro objeto. Es cierto que por referirse a la esfera del tú y de la comunidad de personas, son más próximos y más fáciles de descubrir que por ejemplo las leyes mecánicas de la nautraleza. Pero eso no entraña que su conocimiento sea siempre adecuado. $\mathrm{Y}$ varios iusnaturalistas han sostenido que son difíciles de establecer, al punto de que pocos hombres son capaces de hacerlo. ${ }^{1}$

Pero, en realidad, el precepto no es absoluto, aun si se lo toma en su sencilla formulación bíblica: "no matarás". Pues en el mismo código de la alianza se castiga con la pena de muerte la hechicería, la idolatría y la bestialidad (Ex. 22, 18-20). El precepto va dirigido al particular, pero no a la autoridad pública en cuanto a ésta corresponde la aplicación de las sanciones a los hechos ilícitos. El principio de derecho natural es, pues, "no matar injustamente". Esta limitación no es un mero "expediente", como pretende $B$. Su interpretación no queda ni puede quedar librada a una casuística. Un ataque a cualquier aspecto del suum de cada cual no puede justificar la muerte de un hombre. El caso indiscutible, admitido universalmente es aquél en que matar es necesario para defender la propia vida. La idea de justicia interviene aquí como reguladora de la igualdad entre el bien amenazado o lesionado y el resultado de la respuesta para defenderlo. Por eso la pena de muerte y la guerra sólo se justifican plenamente si pueden subsumirse bajo los conceptos de "defensa" y de "igual retribución".

Es sabido que Scheler ${ }^{2}$ ha amenguado considerablemente las variaciones en la regla del homicidio, sosteniendo que para constituirlo no basta el hecho de la muerte de un hombre sino que se requiere además que sea dado el valor de la persona en el hombre y una intención dirigida hacia su aniquilamiento. De este modo se eliminan varios de los casos enunciados por Wundt $y$ por B., como los sacrificios religiosos, la muerte del hijo, el aborto, la eliminación de contrahechos, etc. Por lo demás, el hecho de que una legislación admita como lícitos

1 Véase mi estudio Algunas reflexiones sobre la justicia y el problema del principio del derecho, XVII y los autores allí citados.

2 En Der Formalismus in der Ethik, V, 6 c. 
ciertos homicidios nada prueba contra el derecho natural, sino sólo que o bien su principio no es conocido adecuadamente o bien que, aun siendo conocido, se lo ha pasado por alto. Finalmente, los datos de la Etnografía constituyen un material delicado, que con frecuencia, por una interpretación apresurada o dirigida por una idea preconcebida, ha conducido a resultados que luego han debido ser rectificados. El error más corriente ha sido aquí pretender inferir de la comprobación de ciertas acciones que se reiteran, la existencia de una norma que las legitima, cuando esta norma no puede ser conocida por sí misma con independencia de los hechos. Es como si un extraño que no pudiera conocer el código penal de una nación, de la frecuencia de los robos pretendiera inferir su licitud.

B) Otras propiedades que se atribuyen al derecho natural, como derecho" "necesario", "en devenir", "ideal" y "teórico" son a los ojos de B., incompatibles con el concepto del derecho.

1) El concepto de "necesario" es muy equívoco. De todas las significaciones con que puede aplicarse al derecho, la que es objeto de la principal crítica de $B$., es aquélla según la cual un precepto jurídico es necesario cuando dado tal hecho es impensable que el derecho pudiera dar otra norma que la que da. Pero según $B$, derecho y nẻcesidad no pueden unirse. El derecho se compadece justamente con lo no necesario, con la libertad de acontecer. La neccsidad reina en la naturaleza por medio de la conexión de causas y efectos. En el derecho reina la conexión de fundamento a consecuencia. Pero la consecuencia no adviene sin más, sino por medio de los hombres que obedecen y que podrían resistir.

Toda ley jurídica podría no ser y por lo tanto no es necesaria. La categoría de "necesidad" introducida en el terreno del derecho sería, así, improcedente, y el concepto de "derecho necesario", una contradictio in adjecto (pp. 426-429).

Pero el concepto de "necesidad" es más equívoco de lo que supone $B$, y su crror ha consistido en no distinguir más significaciones y no haber visto aquella que es precisamente la esencial al derecho. Es claro que el derecho regula, no hechos que ocurren necesariamente, sino las acciones humanas, que son libres. Pero cuando $B$., objeta que la consecuencia jurídica no adviene necesariamente porque depende de que los hombres obedezcan o no, está confundiendo dos esferas que son esencialmente diferentes: la esfera de la disposición jurídica considerada en sí misma y la esfera de su cumplimiento. Es obvio que éste no se sigue necesariamente de la disposición, puesto que el cumplimiento es una acción humana. Pero ningún jurista, sea o no sea iusnaturalista, ha sostenido nunca eso. ${ }^{3}$ La objeción es aquí un golpe en el aire. En cambio, hay necesidad en la esfera de la disposición misma, y, como se verá, más de una. Sólo lo puede negar el que reduzca la necesidad a la conexión de causa y efecto. Pero con esa limi-

${ }^{3}$ La única excepción que conozco es Stahl en su Philosophie des Rechts, pero su tesis no resiste al análisis. Cf. mi Eidética y Aporética del Derecho, Excurso sobre la coacción. 
tación de la significación no se suprime el hecho de que hay otras conexiones en que hay necesidad, si bien ésta es de especie diferente a la que domina en la naturaleza. En la esfera lógica, la conexión entre las premisas y la conclusión del silogismo es una conexión necesaria; pero es una necesidad lógica, no causal. Análogamente en la esfera jurídica la conexión entre la acción y la sanción prevista en la disposición jurídica es una conexión necesaria. Pero esta vez no se trata de una necesidad causal ni lógica sino deontológica. Es la necesidad de un deber ser normativo o dispositivo. No es del caso insistir en una cosa que está hoy bien clara a partir de los análisis de Kelsen en los Hauptprobleme, que en este punto es inobjetable. Pero en los principios del derecho natural hay otra necesidad de deber ser que no es la conexión entre la acción y la sanción, sino más bien anterior a ésta. Es la necesidad del deber ser o del deber no ser de ciertas acciones consideradas en sí mismas con independencia de la sanción. Así, el principio de que los padres deben cuidar de la prole, de que la libertad personal no debe ser suprimida, y otros principios que ya hemos enunciado en la primera parte. Justamente es el deber ser o no ser de estas conductas, el que legitima las sanciones a su incumplimiento, esto es, la conexión necesaria entre el supuesto y la consecuencia jurídica. En ese deber ser de ciertas acciones consideradas en sí mismas reside el fundamento de todas las disposiciones en que el derecho positivo especificará aquéllas.

Pero es claro que la necesidad de este deber ser, como la del que establece la conexión entre el supuesto y la consecuencia, no es una necesidad causal. Lo es tan poco como la necesidad lógica o la necesidad eidética entre las determinaciones de una misma esencia. Si a esas conexiones no se las quiere llamar "necesidad", la cuestión es, entonces, sólo de palabras. Pero con evitar la palabra no se logrará nunca suprimir el hecho fenomenológico de esas conexiones y su especificidad propia.

2) A los que entienden el derecho natural como un derecho "en devenir", B., objeta que si se trata de normas que han de devenir derecho, como tales nunca llegan a actuar como derecho. Pero si se entiende por tales, aquellas que algún día habrán devenido derecho, serán derecho positivo desde ese momento, pero hasta entonces no regían como derecho, ni son derecho ni nada esencialmente jurídico. Hay, ciertamente en el hombre un devenir del derecho. Pero cada precepto jurídico es, desde el instante de su existencia un precepto acabado, no surgido poco a poco. Por consiguiente, un derecho en devenir junto al positivo es una representación ilógica e inútil (pp. 432 ss).

La objeción de $B$., es certera contra semejante derecho "en devenir". Pero el derecho natural no es eso. Si algunos autores del siglo xix lo concibieron así ello puede quizá comprenderse psicológicamente como una posición en retirada frente a la avalancha de las concepciones antiiusnaturalistas, que, al mismo tiempo, quiere ser una defensa, aunque tímida, de un principio que ellos veían, con razón, que era irrenunciable. 
3) Si el derecho natural es determinado como "un derecho ideal", B., admite que todo jurista puede concebir un estado del derecho mejor que el vigente. Pero objeta que ese contenido de su representación no tiene un ser "en sentido científico" ni es un derecho ideal. "Ideal del derecho" no es sinónimo de "derecho ideal". El ideal del derecho es una especie de ideal, mientras que el derecho ideal sería, como especie, coordinado al derecho positivo bajo el género "derecho". Pero el ideal de un derecho no existe como derecho. "La existencia del derecho consiste en que puede ejercer efectos", y en este aspecto el peor derecho positivo sobrepasa al mejor derecho ideal. "Ser derecho significa ser regla vinculadora de la vida; ser ideal significa ser no vinculador. La combinación de ambos conceptos es imposible" (pp. 434-36).

Es claro que si por "derecho ideal" se entiende el mejor orden jurídico concebible o, por lo menos, relativamente mejor que el vigente o positivo, sea en su totalidad, sea en alguna parte de él, ese proyecto, idea, o ideal del derecho no tiene que coincidir necesariamente con los principios del derecho natural, a menos que éste se entienda en el sentido racionalista de la escuela de Wolff. Ese ideal puede referirse a nuevas determinaciones de los principios según las relaciones fácticas que aparezcan en una sociedad, o a mejoras en la técnica del derecho, todo lo cual sobrepasa la esfera del derecho natural. P. ej. si en el contrato de préstamo a interés donde hay contienda sobre la cantidad realmente vertida, el ideal es que se siga el principio general de que cada parte debe probar los hechos que alega o que restablezca la querella non numeratae pecuniae del derecho romano u otra defensa del deudor extorsionado. Cualquiera que fuese la alternativa considerada como "ideal", es evidente que ella no tendría ninguna fuerza vinculatoria, mientras no se convierta en derecho vigente. Entendido el "derecho ideal" en ese sentido, la objeción de $B$., es válida. Pero "derecho ideal" tiene un sentido perfectamente legítimo aplicado al derecho natural. Significa que sus principios tienen un deber ser ideal. No se trata entonces de ideales a realizar en el futuro, sino del deber ser ideal de principios que radican en los valores de la esencia del hombre o de ciertas acciones típicas. Aquí ya no vale la objeción de $B$. No sólo es falso afirmar que "ser ideal significa ser no vinculador" sino que es precisamente el deber ser ideal el fundamento de la vinculatoriedad de toda regla positiva, como lo hemos mostrado en la primera parte. Naturalmente, el deber ser ideal vincula la conciencia pero no tiene la coacción propia del derecho positivo. Si se insiste en llamar "derecho" sólo a un precepto dotado de coactividad, es claro que el derecho natural no es derecho. La cuestión, como ya lo hemos dicho, es entonces meramente de palabras, porque el iusnaturalismo nunca ha sostenido lo contrario. Pero que la existencia del derecho consista en que puede ejercer efectos, es una objeción que se queda corta, porque la vinculatoriedad del deber ser ideal puede muy bien conducir a la acción. En cuanto a que el derecho ideal no tiene "un ser en sentido científico", será mejor no examinar el asunto, porque ni $B$., ni nadie podría decirnos qué significa eso. 
4) Tampoco hay un "derecho teórico". B., la emprende aquí contra muchos positivistas, que emplean esta expresión para revestir sus aspiraciones de reforma con el nombre de derecho. Sus objeciones son, en el fondo, las mismas que ha opuesto al "derecho ideal" (pp. 437-439) y por eso es innecesario examinarlas.

Pero cabe aquí una consideración más general. El hecho de que $B$., con su celo implacable, haya encontrado residuos de iusnaturalismo en los representantes de la escuela histórica y en los mismos positivistas, podría haberlo hecho sospechar que el derecho natural es una idea necesaria al espíritu humano, la expresión de un rasgo esencial del hombre mismo y no una invención arbitraria. El mismo ha reconocido que "todos los hombres son iusnaturalistas natos".

C) Como fuentes del derecho natural se han presentado ya la naturaleza, ya la razón, la moralidad, la prescripción divina, el sentimiento jurídico o la idea del derecho. Cualquiera de ellas funda un "derecho ideal" que, aunque tiene que contradecir necesariamente al derecho positivo, puede censurarlo en varios aspectos. La objeción general que les opone $B$., es ésta: como el ideal del derecho no es derecho, ni siquiera derecho ideal, por las razones que antes adujo (cf. supra B 3) las fuentes del ideal del derecho no pueden ser fuentes del derecho (pp. $442 \mathrm{~s}$.). Nosotros también, pues, nos remitimos a las consideraciones que hemos hecho más arriba. Pero hay que hacer una aclaración: $B$., no distingue entre las fuentes del derecho natural consideradas en sí mismas y esas mismas fuentes como fuentes del derecho positivo. Su falta de rigor se explica porque es sólo el último punto el que le interesa. Pero en realidad ambas cuestiones son diferentes.

Luego $B$., ejecuta la crítica particular de las diferentes fuentes considerándolas en dos grupos:

1) Naturaleza, razón, ethos, ley religiosa. Según $B$., el procedimiento por el cual son elevadas a fuentes del derecho consistiría o bien en que se les añade algo que no está contenido en ellas o bien en que se sustrae algo al concepto del derecho. La razón, p. ej. tiene que ser más que razón y el derecho, menos que derecho. $B$. reconoce que esas fuentes influyen en el contenido del derecho y que nadie discute tal función. Pero agrega que sólo son motivos y fundamentos de explicación; no pueden ser nunca fundamentos de validez de las normas jurídicas (p. 444). Ninguna de ellas puede ser algo vinculatorio, como derecho sin pasar por las comunidades humanas y sus órdenes (p. 446). Es esa validez y vinculatoriedad a lo que $B$. se refiere cuando habla de lo que se añade a la fuente o se sustrae al concepto del derecho.

Pero es justamente esa cuestión la que hemos intentado aclarar en la primera parte, mostrando que el derecho positivo nunca puede tener en sí mismo el fundamento de su validez. Sin duda, si la vinculatoriedad se funda en la coacción el derecho natural no vincula ni es derecho. Pero cuando el hombre se pregunta. por qué ha de acatar los dictados del derecho positivo, ni la coacción ni la validez formal ni la psicosocial (vigencia) constituyen una respuesta satisfactoria. 
La vinculatoriedad del derecho sólo puede fundarse en la validez ideal de ciertos principios de los cuales sean determinaciones las disposiciones del derecho positivo. Entre ellos hay uno que establece que hay que obedecer a la autoridad constituida mientras sus preceptos no aniquilen los derechos esenciales de la persona. Esos principios y esos derechos ya no son más preceptos del derecho positivo, sino los que constituyen el derecho natural. Así, pues, no sólo el contenido, como admite $B$., sino también la validez del derecho positivo sólo encuentra su fundamento en principios suprapositivos.

$B$., objeta que, suponiendo que existieran normas de la razón, inmediatamente surgiria el problema de determinar cuáles de entre ellas serían normas de derecho, puesto que nadie sostiene que toda regla de razón sea también norma de derecho (pp. $452 \mathrm{~s}$ ). Esto último es incontestable, pero no obliga a concluir que la elección sea puramente subjetiva. Principios de derecho serán solamente aquellos que regulen conducta humana intersubjetiva y tengan su fundamento en el suum de la persona humana. No puedo entrar aquí a desarrollar este segundo elemento (el primero es bien conocido) que ha sido dilucidado por mí en otro escrito. 4

Es sorprendente que siendo la naturaleza (y no la razón ni el ethos ni la religión) la fuente primera del derecho natural en el iusnaturalismo clásico (desde los sofistas hasta Thomasius y luego en la neoescolástica) $B$., no le dedique una crítica detallada. Lo único que objeta es que una definición de la naturaleza racional del hombre se aplicaría tanto a un Platón o a un Goethe como a un esquimal, y sería, así, un concepto demasiado vacío, que explicaría poco (p. 448). La objeción denuncia el estado de la cultura antropológica de la generación de $B$. En aquellos decenios de la segunda parte del siglo xIx, la Etnología fue una de las ciencias del día, el estudio de los pueblos lejanos, sobre todo de África y de Oceanía, donde los estados europeos habían implantado su bandera, fue uno de los tópicos de la época. $\mathrm{Y}$ aquellas generaciones, nutridas con el estudio de la psicología, las creencias y costumbres de los pueblos que llamaron "primitivos", acentuando y exagerando a menudo sus diferencias con el hombre europeo, olvidaron (o fingieron olvidar) aquellos elementos que eran idénticos en todos. Esos elementos no han sido anulados por el descubrimiento de los elementos diferenciales. Entre aquéllos se encuentran los que constituyen la esencia de la persona humana, idéntica en todos los hombres. Podemos conceder a $B$. que estos elementos son "pocos" en comparación con los diferenciales. Pero en cuanto a que ese concepto de la naturaleza humana "explicaría poco" ya no podemos seguirlo, puesto que él es el que funda los derechos individuales para todas las personas, por más diferentes que ellas sean. El derecho natural contiene, según ya dijimos, pocos principios. Pero ellos son los fundamentos sobre los que se asienta o debe asentarse todo orden jurídico. Son exactamente com-

4 Cf. del autor Algunas reflexiones sobre la justicia y El problema del principio del derecho en Eidética y Aporética del Derecho, $2^{*}$ ed. Abeledo-Perrot. Buenos Aires 1958. 
parables a los "pocos" pilares sobre los cuales se apoyan nuestros inmensos edificios.

Pero es claro que estos principios no alcanzan para determinar todo el contenido del derecho positivo. Este tendrá necesariamente muchos preceptos según la variada índole de las relaciones fácticas entre los hombres. El derecho natural no hace superfluo al derecho positivo. Las determinaciones de éste sobrepasán la esfera de las simples conclusiones de aquél. Lo cual, empero, no significa que aquellas determinaciones pueden ser arbitrarias. Pues la esfera axiótica contiene otros valores, además de la justicia, la seguridad, la solidaridad, la paz, la certeza, etc., cuya esencia debe determinar el contenido de las disposiciones jurídicas.

$B$. arguye también que si en lugar de la naturaleza y la razón, se apela al ethos y a la revelación, éstos son aún más indeterminados que aquéllos. El ethos no podría ser fuente directa del derecho. Al pretenderlo se olvida que el derecho no existe para sí, sirio para los hombres y a causa de relaciones y conductas humanas frente a las cuales las formas externas accesibles al derecho se hallan por doquier en un proceso, cambiante (pp. 449 s.). Destaca, además, la relatividad de los contenidos de la conciencia moral, remitiéndose a citas de O. Liebman y de Lagarde (p. 450, n. 32).

Dejamos de lado a la revelación, que sólo es invocada como fuente de derecho natural por algunos autores protestantes, y nos limitamos al ethos.

Si se entiende por ethos la moral vigente de un pueblo (ya que la distinción de $B$., excluye su coincidencia con el derecho natural) la objeción mayor de $B$., no es pertinente. ¡ Como si el ethos existiese para sí y no, exactamente como el derecho, para hombres y para relaciones humanas! El ethos es más indeterminado que el derecho en el sentido de que no está por esencia formulado en reglas escritas y no contiene una especificación de tipos de conductas y relaciones tan detalladas como el derecho. Pero si vive realmente en la conciencia de una nación, el derecho positivo tendrá que concordar con él en general. Podrá especificarlo, sin duda. Pero no podrá contradecirlo en puntos capitales so pena de no adquirir vigencia (validez psíquico-social) puesto que la conciencia no podría dividirse asintiendo a reglas contradictorias. ${ }^{5}$ Por otra parte, el hecho de que las conductas y relaciones humanas se hallen en un proceso cambiante no implica que el derecho tenga que modificarse siempre con ellas. Cuando se dice p. ej., que el derecho "tiene que adaptarse" a la conducta, el único significado correcto de este enunciado es que si aparecen nuevas formas, nuevos tipos de relaciones y de acciones, el derecho tendrá que regularlas. Pero establecida la necesidad de esa correspondencia, el derecho como sistema que es de disposiciones, no es el que adapta su contenido al contenido de los hechos, como si p. ej, tuviera que permitir lo que de hecho ocurre. Por el contrario, el derecho establece siempre frente a la multiplicidad de acciones con las que tiene que 1965.

5 Cf. sobre vigencia o validez psico-social la parte I de estas Reflexiones en Diánoia 
habérselas una distinción entre las debidas y las no debidas, entre las prohibidàs y las no prohibidas. En este sentido el derecho no es el que se adapta a las acciones, sino que son éstas las que han de adaptarse al contenido de aquél. Es evidente que el contenido del derecho es y tiene que ser independiente de la dirección que toman los hechos. Toda disposición es por su esencia, en cuanto enunciado de un deber ser, un fenómeno adaptante y no un fenómeno adaptado. $Y$ por eso si bien el derecho positivo puede cambiar, el ritmo de sus cambios es y tiene que ser más lento que el cambio cotidiano y que las direcciones opuestas a que se refiere.

La otra objeción de $B$., contra la posibilidad de que el ethos sea fuente de derecho natural se hace fuerte en la relatividad de los contenidos de la conciencia moral. Esta tesis ha sido posteriormente objeto de importantes rectificaciones sobre todo por parte de Cathrein (Die Einheit des sittlichen Bezeusstsein der Menschheit, 3 vol. 1914) y de Reiner (Pflicht und Neigung. 1951 II parte) y de nuevas interpretaciones por parte de Scheler y de Hartmann en sus conocidas obras de Ética. H. Spiegelberg (Antirelativismus, 1935) ha contribuido también a aclarar muchas cosas. No podemos entrar aqui en análisis detallados, que requerirían largas exposiciones, pero es posible fijar algunos resultados del estado actual de la discusión:

1. Hay un fondo común e idéntico de los contenidos de la conciencia moral, que trasciende a todas sus divergencias. Así, el principio "no hagas a los demás lo que no quieras que te hagan a ti" se encuentra en autores de épocas y lugares tan diferentes como Confucio, Isókrates y el libro de Tobías;

2. Muchas divergencias entre las opiniones morales són más aparentes que reales y se basan en una comprensión insuficiente o errónea de los datos. Así, la muerte de ancianos puede significar no la licitud de la destrucción de la vida, sino el pasaje a una forma superior de existencia; el hecho de que aquí se alabe lo que allá se censura no significa siempre alabanza o censura moral, sino estética, técnica etc.; el relativista olvida que según su propia teoría, el significado de "bueno" y "malo" tiene que variar también y entonces las conductas que son objeto de esos predicados morales ya no son comparables ni pueden ser esgrimidas como prueba de la divergencia de opiniones, puesto que los predicados mismos se han hecho equívocos. Dicho de otro modo: para que los juicios de valor "A es bueno" y "A no es bueno" puedan presentarse como prueba de divergencia de opiniones, es necesario que la palabra "bueno" tenga el mismo sentido en ambos juicios. El relativista, para sostener la relatividad de las opiniones morales, tiene que suponer siempre el carácter absoluto de las significaciones morales. $\mathrm{Y}$ hay que reconocer, por lo menos, que en esto es poco consecuente consigo mismo. 3. A pesar de todas las reducciones anteriores, es indudable que hay disenso de opiniones morales, sea de pueblo a pueblo, sea de individuo a individuo. Pero la comprobación de ese disenso no conduce a la conclusión de que todas las opiniones valgan lo mismo. Cada una de ellas puede ser considerada como un 
intento de fijar y expresar los verdaderos principios del derecho natural o de la moral natural (si se quiere emplear un concepto más amplio) intentos que pueden ser unos más certeros que los otros. Y no puede excluirse que haya uno que haya expresado adecuadamente esos principios. Es lo que en todas las épocas muchos han sostenido del Decálogo. Y no debe ser pasado por alto que cada ethos, si bien es propio de un pueblo y diferente en parte del de otro pueblo, nunca se presenta a sí mismo como limitando su vigencia a ese pueblo, sino con la pretensión de una vigencia universal. $Y$ Éste es un testimonio humano, de que en la conciencia de todos los hombres está esbozada la idea de que los principios morales han de ser universales en su validez ideal.

4. De lo anterior resulta que ni la conciencia moral ni el ethos deben ser considerados como las únicas formas del conocimiento moral. Este consiste en su forma prístina en la intuición de los valores y de los principios que en ellos se fundan, intuición que purificada por el análisis y la reflexión crítica puede conducir a un conocimiento objetivo de los principios, más allá de los datos de la conciencia moral y del ethos. ${ }^{6}$

2) El sentimiento jurídico, el sentido jurídico, la conciencia del derecho y la idea del derecho constituyen el segundo grupo de pretendidas fuentes del derecho natural que $B$. critica. Lo que la diferencia del primer grupo es que tienen carácter intuitivo (p. 464) B. encuentra inexplicable que lo objetivamente normativo pueda salir de los productos del sentimiento y del pensar. Se vincula el sentimiento o el "sentido", que son procesos internos, con el "derecho", sin aclarar su sentido, y luego de ahí ha de resultar una instancia objetiva, esto es, las normas coactivas de las acciones (p. 455). La objeción supone que estas fuentes crean el derecho natural. $\mathrm{Y}$ así es, en efecto, en muchos de los que propusieron la teoría del sentimiento jurídico como un sucedáneo del iusnaturalismo clásico (Gustav y Max Rümelin, Jhering, etc.). Entonces la objeción es válida y habría que admitir también que ese supuesto sentimiento, sentido, etc., no es un fundamento indivisible que pueda explicar todo el contenido del derecho, sino un compositum de otras fuentes (p. 456). La objeción es válida en cuanto se refiere al derecho natural, porque éste, por definición, no puede ser un producto de los actos subjetivos. Pero tomada en su sentido general -y éste es el que le da. $B$ - - la objeción no sólo no es válida sino que no se ve cómo las cosas podrían ser de otro modo al que es precisamente objetado. ¿ No nace una teoría científica, esto es, algo objetivo, de actos de pensar? ¿No surge una obra de arte del sentimiento, de las intuiciones, de las ideas del artista? Pero el derecho natural es, como la naturaleza y sus leyes (en el sentido de las ciencias naturales) algo objetivo. Por consiguiente, hablar de fuentes sólo puede significar aquí "fuentes del conocimiento" del derecho y no "fuentes de la producción del derecho". Pero

6 Para toda esta cuestión de la relatividad cf. lo dicho por el autor en Algunas reflexiones sobre la justicia etc. IV. 
si se supone que para ello hay un órgano del derecho en el hombre y que es innato, $B$. objeta que entonces tendrían que poseer ese órgano todos los hombres $-\mathrm{y}$ no simplemente muchos- lo cual sería afirmar demasiado. Las tesis remite a un sentido moral que sería fuente de la legislación moral. Pero desconoce el hecho de que de ese sentido moral fluyen concepciones morales muy contradictorias (pp. 457 s.). Pues en realidad, no hay una conciencia moral con un contenido innato, porque los hombres nacen con disposiciones desiguales a las que se agregan la educación, la experiencia, etc. Tampoco hay un sentimiento específico del derecho innato igual en todos los hombres, pues depende del saber, y éste de influjos de tiempo y de lugar (pp. 462 ss.).

En realidad, estas últimas objeciones repiten la formulada anteriormente sobre la variabilidad de los contenidos del ethos y de la conciencia moral, que ahora es referida al sentimiento y al sentido jurídico. A este respecto no tenemos por qué repetir lo que hemos dicho más arriba ( $\mathrm{C}, 1$ a propósito del ethos 1,2 , 3 y 4 ).

Por otro lado hay que reconocer que mucho de lo que $B$. objeta al sentimiento jurídico es exacto (V. además las objeciones de pp. 465-472). Pero, al mismo tiempo hay que destacar que la tesis que pretende fundar el derecho natural en el sentimiento o en un sentido jurídico es una doctrina tardía de algunos autores del siglo $\mathrm{xrx}$, que se ha prolongado hasta nosotros ( $\mathrm{p}$. ej. Isay) para sustituir al derecho natural clásico.

Es cierto que ni el derecho positivo ni el natural tienen su fuente primera en el sentimiento. No hay un sentimiento jurídico que pudiera dar a conocer las diversas normas del derecho. Hay sí un sentimiento de lo justo, que puede ser una guía para las decisiones particulares. Pero el derecho natural o se basa en intelecciones claras o es como si no existiese.

Finalmente $B$. critica las doctrinas que ponen como fuente a la "idea del derecho". Como esta expresión encierra muchas significaciones, no nos referiremos más que a las dos realmente importantes:

a) la "idea del derecho" puede significar la justicia. En este caso $B$. objeta que ésta no nos da preceptos jurídicos sino la dirección de una consecuencia comparativa en la que tanto los miembros de la comparación como el criterio vienen dados de otro lado. En este sentido la idea del derecho no es capaz de dar principios y proposiciones jurídicas materiales (pp. $474 \mathrm{~s}$.).

Estas reflexiones coinciden con las que yo mismo he formulado en mi estudio ya varias veces citado. ${ }^{7} \mathrm{La}$ idea de la justicia por sí sola no es suficiente para regular el derecho positivo. Por eso fallan todas las teorías que pretenden sustituir el derecho natural por la justicia. Pero el iusnaturalismo clásico, lejos de identificarlas, distinguió ambas ideas y apoyó siempre la justicia en el derecho natural. La objeción de $B$. contiene, pues, una verdad al destacar el carácter

7 Algunas reflexiones sobre la justicia etc. s. todo $\S \mathrm{V}$ y ss. 
'formal de la justicia, pero no es una objeción más contra el derecho natural sino contra sus sucedáneos.

b) B. admite que la Filosofía del derecho tiene que ocuparse con las ideas materiales del derecho, que han inspirado a las instituciones jurídicas. Pues el derecho está al servicio de tales ideas. Pero son ideas "prácticas", lo que significa:

1) que surgen de motivos morales, económicos, políticos, es decir, relativos al hombre;

2) que son abstraídas del propio derecho práctico. No son innatas sino halladas en los fenómenos jurídicos;

3) son pensamientos con energía, que impulsan a su realización el mundo de los fenómenos externos (pp. 475 ss.). En éste sentido $B$., reconoce que las ideas del derecho pueden prestar servicios. Pero en todo caso se entiende el derecho tal como debiera ser, lo cual, a su vez, viene de la conciencia moral, de la razón, etc., que antes ya fueron criticadas (p. 478).

En estas consideraciones salta a la vista la contradicción en sostener, por un lado, que esas ideas han inspirado al derecho positivo $\mathrm{y}$, por otro, que son abstraídas de él. Si lo que $B$. quiere decir es que el filósofo para conocerlas necesita abstraerlas del derecho positivo, ése no sería más que un conocimiento. derivado, que remite a un conocimiento originario, el cual necesariamente debe ser previo al derecho positivo. El mismo $B$. lo reconoce al declarar que surgen de motivos morales, económicos, políticos, que vienen de la conciencia moral, de la razón, etc. Pero así presentada, la tesis de este origen de las ideas materiales del derecho no requiere una nueva crítica, pues remite de suyo a la que hemos hecho antes de su crítica a la razón, a la naturaleza, etc. La doctrina de la "idea" del derecho es, como la del "sentimiento jurídico" un tímido sucedáneo de la doctrina clásica del derecho natural, excogitada para épocas de indigencia filosófica.

Pero es muy significativo que $B$. después de haber pretendido que sólo el derecho positivo es una "energía activa", reconozca ahora que las ideas del derecho son pensamientos "con energía" que impulsan a su realización.

Hemos dicho que Jurisprudenz und Rechtsphilosophie era la más completa Summa crítica contra el iusnaturalismo. Después de ella muchas veces se ha reabierto el debate, generalmente repitiendo sus argumentos, alguna vez con argumentos nuevos, como es el caso de Kelsen. De todos modos, haciendo la crítica de aquella Summa hemos podido advertir que las objeciones a la doctrina del derechó natural son bien endebles o se basan en equívocos. $Y$ es por eso que ha resurgido siempre. Pues cuando una teoría es blanco de objeciones certeras, la teoría muere irremisiblemente. Así ocurrió con el sistema ptolemaico o con la teoría del flogisto.

Guando se dice que el derecho natural está enterrado, en verdad hay que entender que ha sido enterrado como la semilla para florecer de nuevo. Por 
cierto que fue declarado muerto sucesivamente varias veces: lo que quiere decir que cada nueva partida de defunción demostraba que la anterior era falsa. Y así ha sido hasta el presente.

Juan Llambías de Azevedo 